\title{
Desmaterialización e inmaterialidad en el contexto contemporáneo del Diseño
}

\section{Lemgruber Queiroz, Leila}

Resumen: Este artículo incluye

reflexiones sobre la importancia de considerar, en la actitud proyectual del diseño, la desmaterialización y la inmaterialidad. El enfoque va dirigido a los atributos de sostenibilidad en el escenario de la Posmodernidad. Lo que se pretende recalcar son paradigmas innovadores sobre la configuración de artefacto que decontruyen el sistema convencional de producción, distribución y consumo. Las cuestiones que se tratan en el texto se refieren a los factores condicionantes de la cultura material, así como de la cultura inmaterial.

Palabras clave: Desmaterialización Inmaterialidad - Posmodernidad Sostenibilidad - Diseño.

\section{Cuadernos del Centro de Estudios de Diseño y Comunicación №70}

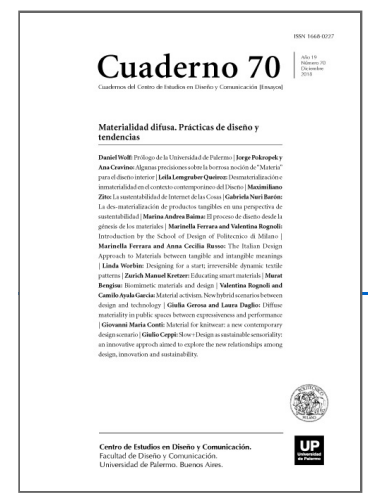

ISSN: 1668-0227

Materialidad difusa.

Prácticas de diseño y

tendencias

Año XIX, Diciembre 2018, Buenos Aires, Argentina | 172 páginas

descargar PDF

ver índice de la publicación

Ver todos los libros de la publicación

compartir en Facebook

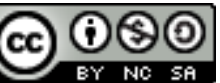

Esta obra está bajo una Licencia Creative Commons Atribución-NoComercialCompartirlgual 4.0 Internacional

(*) Doctora y Master en Diseño de la PUC-Rio con MBE en Gestión de Sustentabilidad por el Instituto de Economía de UFRJ.

Introducción

En un mundo lleno de objetos, lo que se pone en cuestión es la deconstrucción del concepto clásico de la cultura material. En esta visión, el campo del diseño imprime su marca a través de la configuración de los objetos. Ya sea por su rediseño o la introducción de nuevos artefactos. A partir de este escenario, se presenta una reflexión sobre la posibilidad de deconstruir el concepto sobre el campo del diseño que se está relacionado con esta actitud proyectual sobre la configuración de objetos. Por lo tanto, se tratará aquí este proceso de deconstrucción a través de dos condiciones anteriores al proyecto de diseño: desmaterialización e inmaterialidad. Cabe destacar que estas dos condiciones se las pondrán aquí en ejes temáticos distintos, aunque tienen una raíz común. De esta manera, lo que se pretende señalar son algunos atributos del campo de la sostenibilidad en el escenario contemporáneo, entendido aquí como la posmodernidad, que conducen a la reinvención de nuevos hábitos y paradigmas en el campo del diseño. 
Lo que se presentará en este texto se refiere a las preguntas y reflexiones sobre qué y cómo configurar objetos en la era de la posmodernidad. Sobre todo, porque la formulación de los problemas de posmodernidad es una oscura tarea. El volatilidad y la fragmentación, atributos de esta edad, impiden una visualización clara y directa de sus problemas.

Teniendo en cuenta el panorama contemporáneo, nuestra reflexión va dirigida a la movilidad, con gran aceleración. Utilizamos el concepto de Bauman sobre la Modernidad Líquida con el fin de que logramos sumergirnos en este mundo en el que el grado de éxito se mide por el estándar de la posesión, consumo de bienes materiales, demasiada información y, más aún, involucrados que están los individuos en la desechabilidad permanente, por lo que corre siempre en busca de la próxima la innovación, objetual o virtual. Impera la aceptación de lo efímero, lo descontinuo y los cambios caóticos.

Las cuestiones relacionadas con la sostenibilidad, para la configuración de nuevos artefactos, absorben no solo el sentido fragmentario, pero los riesgos y las incertidumbres de la escena contemporánea. Por lo tanto, se hace urgente introducir diferentes paradigmas en los procesos de configuración, producción, distribución y consumo.

Si movemos nuestro foco al campo del diseño, podemos asumir una actitud, a primera vista radical, de que el diseño proporciona una mejor calidad de vida a través de proyecto de múltiples artefactos, cuando lo que importa sobre todo es el mantenimiento de la producción de mercancías.

Se habla que el diseño cumple con las necesidades, cuando sabemos que éstos se construyen en rebeldía del sujeto e incorporadas a su vida como inexorablemente esenciales. Inventadas como fábulas. A veces, incluso placenteras.

La reconfiguración de la cadena de suministro contemporáneo, impuesta por el capitalismo flexible, permite la aceleración de los impactos ambientales y sociales. Sobre todo porque la no linealidad de los procesos dificulta la visibilidad de todo el sistema productivo. Destacamos aquí que la industria contemporánea presenta estas características: la materia prima puede ser de una región del planeta y su fabricación de la región opuesta. Pero los usuarios están esparcidos por todas las regiones. Sin embargo, el producto final pertenece a la misma marca. Esta es la economía descentralizada del capitalismo flexible.

Cabe señalar que los residuos derivados de la producción y consumo afectan nuestros suelos y migraran, a veces, a países que acepten absorben materiales contaminados. La cuestión del proceso del reciclaje no se desarrollará aquí ya que entendemos que es un proceso ya comprobadamente envuelto con características económicas negativas por su alto coste de energía y logístico.

Al hacer referencia puntualmente al diseño, estando él al servicio de la economía de mercado, destacamos su colaboración para que el papel de comando que se ha atribuido a los artefactos se ponga exacerbado. Se introduce este comando a un ritmo creciente que supera el proyecto del propio artefacto para instalarse en la construcción de escenarios de nuestra vida cotidiana. Todo se convierte en "diseño": desde el olor que se debe oler hasta la estética que se debe tragar.

Preguntar y reflexionar sobre estas premisas, que han producido la industria de consumo, es factor determinante al oficio del diseñador. 
Varios teóricos han abordado en sus escritos el papel del diseño en el mundo contemporáneo mediante la promoción de la reflexión crítica. Sin embargo, Hal Foster ha realizado una crítica más aguda. En el artículo Diseño y Delito, Foster se deshilacha el tejido del diseño contemporáneo con sus conceptualizaciones insertadas en el contexto actual.

Según Foster, la estética y lo utilitario no se encuentran solo fundidos, pero por encima de todo incluidos en todo lo que pasa a nuestro alrededor. Desde los vaqueros a los genes como recalca Foster.

Hal Foster, en el siglo XXI insinúa el papel "desviado" del diseño. Su acción maléfica está esparcida en todos los grupos sociales. Según el autor, hay demasiado diseño en el mundo hoy en día. La penetración del diseño en la vida contemporánea es total. No hay espacio para escapar de este marco impuesto por un sistema. En este sistema, el mundo del diseño total se impone como nuevo ingrediente para poner en marcha la competitividad en los negocios, haciendo uso cada vez más de la seducción. A causa de esta situación, el embalaje lleva mayor importancia que el producto que lo contiene.

Foster desarrolla su pensamiento que justifica la inflación del diseño en el escenario actual, a causa de vectores como la flexibilidad de la economía, el valor exacerbado que asigna a las marcas y al crecimiento de industrias medianas en la economía. En esta política económica de diseño, no se piensa el producto como un objeto a producir, sino como una cosa a manipular, es decir, ser "diseñado" y "rediseñado", consumido y reconsumido. De esta manera, las cuestiones que se desarrollan en la reflexión crítica sobre el papel del diseño en el escenario posmoderno, se refieren, en este texto, acerca de otras posibilidades que interfieren en la materialidad como condición previa proyectiva.

La reflexión sobre las condiciones proyectuales: desmaterialización e inmaterialidad

Hay una conformidad de pensamiento que impregna la sociedad, entre la incompatibilidad del proceso industrial y el medio ambiente. Los ecologistas caracterizan la industria como destructiva, a causa de la forma convencional de uso de los recursos naturales, su procesamiento y posterior desecho de sus productos en la basura. Por otro lado, los industriales ven el ecologismo como un obstáculo para la producción y el crecimiento. Para que el medio ambiente sea "saludable", según el pensamiento convencional, las industrias necesitan encontrarse bajo cierto control, a través de reglamentos. Otra corriente de pensamiento con respecto a los límites que se deben imponer al consumo: compre menos, gaste menos energía, tenga menos hijos y... reduzca su basura. Usando este paradigma, los seres humanos necesitan hacer algunos sacrificios para salvar el planeta.

McDonough\&Braungart comienzan el libro Cradle to Cradle, citando el pensamiento de Einstein: "El mundo no va a superar su crisis actual utilizando el mismo pensamiento que ha creado esta situación." A partir de esta concepción, los autores introducen un nuevo modelo de producción. La cuestión clave no es reducir, minimizar o evitar el desperdicio, sino eliminar el propio concepto de generación de impactos, a través de nuevos paradigmas, a través del diseño sistémico.

¿Cómo puede el ser humano vivir sin culpa en su planeta, disfrutando de las comodidades que proporcionan el mundo contemporáneo? Esta pregunta contiene todas las cuestiones relacionadas con el dilema entre el consumo y la posibilidad de degradación del medio ambiente. 
La sociedad actual se refiere al individuo como un "consumidor". De hecho, en realidad poco se consume. Se puede hablar de lo que se come o bebe como ejemplos de lo que se consume. El resto está diseñado para arrojar fuera cuando su uso tiene el orden decretado, por el propio individuo o por el sistema industrial. Sin dejar de mencionar que además de la acumulación de la materia desechada, se desecha también toda la toxicidad presente en el producto, lo que causa efectos desastrosos en el ecosistema. De esta manera, el aire, el agua, el suelo no absorben de forma segura los desechos, a menos que estén exentos de riesgo: sanos y biodegradables.

Fritjof Capra desarrolla su pensamiento sobre la Ecología basado en una perspectiva sistémica. De acuerdo con este punto de vista, las propiedades esenciales de un organismo o un sistema vivo son propiedades del todo, que ninguna de las partes tiene por separado. Estas ideas que vienen de los biólogos organicistas durante la primera mitad del siglo XX han ayudado a introducir una nueva forma de pensar, el pensamiento sistémico.

Esta comprensión de que los sistemas son totalidades integradas, ha desatado una revolución en distintos campos del conocimiento científico. La física cuántica ha cambiado la forma con la que, desde Newton, se creía que los fenómenos físicos podrían "reducirse a las propiedades de las partículas materiales rígidas y sólidas". La teoría cuántica ha presentado el hecho de que los objetos materiales antes identificados por la física clásica como siendo sólidos, de hecho se disuelven "en el nivel subatómico en estándares de probabilidades similares a las ondas". Por lo tanto, en la Teoría Cuántica no llegamos a una sola cosa, sino también a las interconexiones. Los componentes de las moléculas y los átomos descritos como partículas subatómicas, no pueden considerarse como entidades aisladas sino de acuerdo con sus interrelaciones.

A partir de esta concepción, sobre la Ecología, se puede entender más claramente, el pensamiento de Manzini sobre la Ecología Industrial. Cabe señalar que el modelo de la Ecología Industrial, el sistema de producción y de consumo tiende a organizarse acercándose del funcionamiento de un sistema natural que combinan los "tecnociclos y biociclos".

Tecnociclos se definen como el conjunto de procesos tecnológicos cerrado en sí mismo, por lo que busca la mayor proximidad posible a una autonomía del medio ambiente, que no tiene en él ninguna influencia. En este caso, la orientación se mueve a la no interferencia en la biosfera. Este proceso es una forma de buscar, pero en su totalidad, no se puede lograrlo, porque todo lo que el sistema de producción, habrá el intercambio de energía y producción de entropía.

En cuanto a los biociclos, el objetivo de dirigirse un sistema a la biocompatibilidad es hacer que el sistema de producción y el consumo se basa en recursos renovables sin crear residuos que no se absorben por los ciclos naturales.

En la definición de la Ecología Industrial, el término residuo pasa a tener la connotación de un nuevo proceso de producción. De hecho, la propuesta a través de la puesta en marcha de la Ecología Industrial se puede comparar con la propiedad de buscar un nuevo estado de equilibrio, como sistemas auto-organizadores, por el ejemplo los seres vivos que todos sus componentes están unidos por una red de interdependencia, que implican flujos de materia y energía en ciclos continuos. 
La "vecindad" industrial es otro factor relevante en ecología industrial. Las actividades que se han considerado complementarias requieren una proximidad territorial para que haya una simbiosis industrial. En consecuencia, en el sistema de la Ecología Industrial, es necesaria la presencia de la red de comunicaciones. Cabe señalar que esta red de comunicación pertenece al paradigma del pensamiento sistémico. Como informa McDonough \& Braungart, hay dos metabolismos en el planeta Tierra. El primero es un metabolismo biológico, la biosfera, los ciclos de la naturaleza. El segundo es un metabolismo técnico, la tecnósfera, los ciclos de la industria. Proyectando correctamente, todos los productos y materiales fabricados por la industria, se convertirán en alimentos seguros para estos dos metabolismos, lo que proporciona nutrientes para producir algo nuevo.

El nutriente biológico es un material o producto que está diseñado para volver al ciclo biológico. Se consumirán este material los microorganismos en el suelo y otros animales. Según los autores, la mayoría de los embalajes debe pertenecer a esta clase de material, ya que no tiene sentido que duran más décadas o siglos que sus contenidos. Como un ejemplo, los embalajes de crema dental, champú, yogur y muchos otros. En este caso, nos estamos refiriendo a un proceso de desmaterialización de los artefactos. Se programa la materia prima que está relacionada con estos artefactos para descomponerse y absorberse por los procesos que pertenecen al medio ambiente natural. En esta clase de artefactos, incluyen aquellos biodegradables.

Hay que señalar aquí que se considerarán con atributos de desmaterialización también aquellos que están diseñados para absorberse como alimento para el sujeto como un usuario del artefacto. Por ejemplo, con el fin de abordar el tema de la desnutrición en India, una gran empresa de productos alimenticios ha propuesto la introducción de un embalaje de yogur que, después de haber consumido su contenido, podría hervirlo y convertírselo en comida. Otro ejemplo son los platos de sopa que se sirven a la población sin hogar cuyos embalajes son comestibles.

Hacemos hincapié como condición de la desmaterialización la existencia, en algún momento anterior, de la materia que compone del artefacto. Especialmente porque hay casos en los que la materialización solo causa una disminución de la suma final de la materia prima en la fabricación del artefacto. Puede ocurrir esta sustracción de materia prima total en el artefacto, de forma tan radical, mediante la sustitución de la materia prima original. En ambas situaciones, el artefacto se convierte en algo más ligero, con su composición más favorable a impactos relacionados con su producción, distribución y consumo. En este caso, hay una disminución en el proceso entrópico.

Cabe recalcar la diferencia semántica que aquí ponemos en el término desmaterialización y el otro, inmaterialidad. Cuando evocamos la desmaterialización de los artefactos, señalamos la retirada, la sustracción de parte del material que constituye el artefacto en cuestión. Llegando al punto de, en algunos casos, la posibilidad de disolución total de la materia. Por lo tanto, no estamos aquí rechazando la existencia de la materia de los artefactos, pero se- ñalando dos maneras distintas: en primer lugar, la desmaterialización puede ocurrir por la desintegración de la materia que compone el artefacto. En este caso, estamos hablando de la condición de biodegradabilidad. Esta biodegradabilidad se produce mediante el desecho en un medio adecuado o la posibilidad de ser un material compuesto apto para el consumo humano. En segundo lugar, se ha tratado otro camino descrito en este documento mediante la disminución del volumen total de la materia prima en la fabricación de artefactos. 
Trataremos ahora de la inmaterialidad. En este caso, conviene sacar a colación las tecnologías digitales que están al servicio del diseño contemporáneo. En este caso, destacamos la realidad aumentada, así como todos los procesos que hacen uso de la holografía, tanto en el alcance del diseño de los juegos como en el diseño que participa en la elaboración de procesos innovadores para la investigación científica, tales como imágenes holográficas del cuerpo humano.

Cabe señalar que esta falta de materialidad también se identifica cuando tratamos de la cultura inmaterial. En lo concerniente al diseño, cabe considerar, por ejemplo, el conocimiento tradicional de una determinada comunidad como un estudio de caso de su investigación. Por lo tanto, la cultura, la tradición, el arte y todas las formas de ser de un determinado grupo de personas conforman lo que llamamos cultura inmaterial.

Para que podamos extender nuestra reflexión sobre la inmaterialidad, recurrimos a Vilém Flusser al relatar sobre la importancia de "no-cosa" en la escena contemporánea. No hace mucho tiempo, las "cosas" invadían los espacios y las vidas de las personas. Pero ahora las "no-cosas" suplantan las "cosas". Y estas "no-cosas" se denominan información. Cabe resaltar que esta información pertenece a la categoría de lo inmaterial tales como los datos almacenados en el computador, hologramas, los softwares y las imágenes electrónicas de la pantalla de la televisión. Estamos interesados en la actualidad en consumir información. Por el contrario, una gran parte de la sociedad está ocupándose en la producción de esta información. En esta familia de información, hay también el diseño de experiencias. Experimentar distintos momentos: un nuevo valor en el mercado de la posmodernidad. En esta nueva lógica surge el Homo Ludens.

Las manos, esenciales para el Homo Faber, perdieron su importancia. Las puntas de los dedos comandan la inmaterialidad. Al pulsar una tecla, se abre un mundo infinito de experiencias: inmaterialidad se presenta al Homo Ludens.

\section{Consideraciones finales}

En este texto, pretendemos poner de relieve los procesos innovadores que cruzan la desmaterialización de los artefactos y también su inmaterialidad. Cabe señalar que este artículo tiene como meta imprimir una reflexión que no se agota en estas páginas. Por encima de todo, hace hincapié en que los sistemas innovadores también pueden ser meras utopías. Pero son que podremos movernos hacia una nueva lógica de permanencia del sujeto en el mundo. Y esta permanencia depende, en gran medida, de cómo manejamos una nueva mirada al campo del diseño. La desmaterialización y la inmaterialidad son atributos de sostenibilidad. Por lo tanto, la actitud proyectual del diseño en nuestra contemporaneidad hace falta insertar las condiciones a priori que están relacionadas con el campo de la sostenibilidad.

\section{Referencias}

Capra, F. (2001). A Teia da Vida: uma nova compreensão dos sistemas vivos. São Paulo: Cultrix.

Bauman, Z. (2001). Modernidade Líquida. Traducción de Plínio Dentzien. Rio de Janeiro: Zahar.

Flusser, V. (2007). O mundo codificado: por uma filosofia do design e da comunicação. Traducción de Raquel Abi-Samara. Org. Rafael Cardoso. São Paulo: Cosac Naify. 
Foster, H. (2002). Design and Crime: and other diatribes. London: Verso, part two.

Manzini, E. e Vezzoli, C. (2002). O Desenvolvimento de Produtos Sustentáveis: os Requisitos Ambientais dos Produtos Industriais. São Paulo: Edusp.

Mcdonough, W. \& Braungart, M. (2002). Cradle to Cradle: remaking the way we make things. Nueva York: North Point Press. Queiroz, L. L. (2014). Utopia da sustentabilidade e transgressões no design. Rio de Janeiro: 7letras.

Abstract: This paper includes reflections on the importance of considering dematerialisation and immateriality in the projectual attitude of design. The focus is directed to the sustainability attributes in the Post-Modernity scenario. What it is intended to highlight are innovative paradigms of the configuration of artifacts that deconstruct the conventional system of production, distribution, and consumption. The issues addressed in the text refer to the conditioning factors of material culture as well as immaterial culture.

Key words: Dematerialisation - Immateriality - Postmodernity - Sustainability - Design

Resumo: Este artigo inclui reflexões sobre a importância de considerar, na atitude Projetual do design, a desmaterialização e a imaterialidade. O enfoque dirige-se aos atributos de sustentabilidade na cena da pósmodernidade. Pretende-se recalcar paradigmas inovadores sobre a configuração de artefatos que desconstroem o sistema convencional de produção, distribuição e consumo. Tratam-se os temas relacionados com os fatores condicionantes da cultura material e imaterial.

Palavras chave: desmaterialização - imaterialidade - pós-modernidade - sustentabilidade - design

Desmaterialización e inmaterialidad en el contexto contemporáneo del Diseño fue publicado de la página 29 a página35 en Cuadernos del Centro de Estudios de Diseño y Comunicación №70 